\title{
Return to Work and Its Relation to Financial Distress among Iranian Cancer Survivors
}

\author{
Mostafa Ghasempour ${ }^{1 *}$,Azad Rahmani ${ }^{2}$,Arefeh Davoodi ${ }^{1}$,Zahra Sheikhalipour ${ }^{1}$, \\ Jamal Evazie Ziaeei ${ }^{2}$, Fariba Abri $^{3}$
}

\begin{abstract}
Background: Return to work after treatment completion is important for both cancer survivors and society. Financial distress is one of the factors that may influence the return to work in cancer survivors. However, this relationship has not been well investigated. This study aimed to determine the rate of return to work and its relation to financial distress among Iranian cancer survivors. Materials and Methods: This descriptive-correlational study was undertaken among 165 cancer survivors who completed their initial treatments and had no signs of active cancer. The Return to Work questionnaire and Financial Distress/Financial Well-Being Scale were used for data collection. Data were analyzed using SPSS statistical software. Results: After initial treatments, 120 cancer survivors $(\mathbf{7 2 \%}$ ) had returned to work, of which 50 patients $(\mathbf{4 2 \%})$ had returned to full-time work and $\mathbf{7 0}(\mathbf{5 8 \%})$ reduced their work hours and returned to part-time work. Cancer survivors also reported high levels of financial distress. In addition, the financial distress was lower among patients who had returned completely to work, in comparison to patients who had quit working for cancer-related reasons $(p=0.001)$ or returned to work as part-time workers $(\mathrm{p}=\mathbf{0 . 0 0 1})$. Conclusions: The findings showed that a high percent of Iranian cancer survivors had not returned to their jobs or considerably reduced working hours after treatment completion. Accordingly, due to high levels of financial distress experienced by participants and its relation to return to work, designing rehabilitation programs to facilitate cancer survivor return to work should be considered.
\end{abstract}

Keywords: Return to work - financial distress - cancer - cancer survivors - Iran

Asian Pac J Cancer Prev, 16 (6), 2257-2261

\section{Introduction}

Cancer is the third leading cause of deaths in the world. According to international statistics, 12.7 million new cancer cases and 7.6 million cancer- related deaths were recorded in 2008 (Jemal et al., 2011). In our country, Iran, cancer is the third common cause of death after cardiovascular diseases and road traffic accidents (Mousavi et al., 2009). Advances in current treatments and innovation of new therapies and early detection techniques have dramatically increased the number of cancer survivors in recent years (Rowland and Yancik, 2006). It is estimated that 13.7 million people with a history of cancer were alive in the United States in early 2012. The majority of those patients $(64 \%)$ were diagnosed during the five or more years ago, and $15 \%$ were diagnosed 20 or more years ago (Siegel et al., 2012).

The diagnosis and treatment of cancer often causes lots of complications for patients in both physical and psychological dimensions (Wen and Gustafson., 2004; Faghani et al., 2014; Tuncay, 2014). These complications may include increased dependence and sense of vulnerability, pain suffering, negative thoughts and lack of confidence (Jemal et al., 2011), as well as, impaired daily functioning and social isolation (Helgeson and Cohen., 1996; Afrooz et al., 2014). These problems, plus the frequent hospitalizations and use of invasive procedures had reduced the patients' quality of life (Keogh and MacLeod, 2012). Also, cancer diagnosis/treatment can lead to financial difficulties for many cancer patients and their caregivers (Wen and Gustafson, 2004; Rowland and Baker., 2005) In this regard, the findings of studies in Canada (Lauzier et al., 2008) and United States (Hamilton et al., 2013) showed that financial distress caused by the cancer diagnosis/treatment is even prevalent among cancer patients in developed countries.

According to recent literature, 90 thousand people in the UK annually experience the cancer diagnosis at the working age and almost half of the cancer survivors are younger than 65 years (Short et al., 2005). Accordingly, it is expected that most of cancer survivors will be able to resume their daily activity including return to work 
during or after the treatment completion (Schultz et al., 2002). Returning to work is essential for personal identity and continuity of social relationship, as well as, inspires a sense of well-being and power in cancer survivors (Peteet., 2000; Tan et al., 2012). Additionally, returning to work can improve patients' quality of life and is a symbol of recovery and regaining a normal life (Maunsell et al., 1999; Spelten et al., 2002; Kennedy et al., 2007) . As well, returning to work help patients to overcome the negative consequences of disease and treatments, and has positive financial outcomes for both cancer survivors and the society (Ferrell et al., 1997; van Muijen et al., 2013; Han et al., 2014).

A number of studies in different parts of United States (Bradley and Bednarek., 2002; Schultz et al., 2002; Hoffman., 2005), Canada (Maunsell et al., 2004), and Finland (Taskila-Åbrandt et al., 2004) showed that cancer had no significant impact on return to work in cancer survivors. However, some other studies in United States (Bradley et al., 2005; Short et al., 2005) and Norway (Abrahamsen et al., 1998; Gudbergsson et al., 2006) suggested that cancer patients may experience impairment in both physical and psychological wellbeing which resulted in diminished ability to work after cancer treatments. More recently, the results of one study showed that the risk of unemployment was significantly higher in cancer survivors compared to healthy controls (Feuerstein et al., 2010). Another study showed that on average 62\% of cancer survivors return to work during or after the treatment (Muzzin et al., 1994).

Financial distress is one of the main factors that influence the return to work in cancer survivors. Most of patients in a study by Main et al. reported that financial distress and insurance problems were the main influencing factors on their return to work (Main et al., 2005). In a study in France, Fantoni et al. (2010) reported that older age, type of treatment, disease stage, and financial problems were associated with return to work in breast cancer survivors. Also, in another study in the UK, approximately $50 \%$ of participants reported financial difficulties were the main reason for returning to work after treatment completion (Kennedy et al., 2007). However, in a study by Spelten et al. (2002) demographic factors such as income were not significantly associated with return to work. Further investigations regarding the role of socioeconomic factors on returning to work in cancer survivors had been recommended in previous studies (Spelten et al., 2002; Johnsson et al., 2007).

To date, there have been no studies that examined the association of financial distress with returning to work among cancer survivors in Iran or other Middle Eastern countries. Accordingly, the aim of this study was to determine the rate of return to work and its relation to financial distress among Iranian cancer survivors.

\section{Materials and Methods}

This descriptive-correlational study was conducted in both educational and private hospitals in Tabriz, the capital of East Azerbaijan Province in northeast of Iran. The study population included all patients who were admitted to the centers during the sampling period. Inclusion criteria were: having confirmed cancer diagnosis, be at least 18 years old, willing to participate in the study, completion of primary treatment, no signs of active cancer, and employed at the time of diagnosis. The sample size $(n=195)$ was calculated based on a pilot study. Considering sample attrition, a sample of 175 eligible patients was invited to participate in the study. Overall, 165 subjects accepted to be enrolled (response rate $=94 \%$ ).

The instrument for data collection composed of three main parts. The first part was a checklist of demographic characteristics of patients and was completed based on patients self-report or their medical records. The second part was related to Return to Work questionnaire and designed according to a previous related study (Nilsson et al., 2013). In this section patients were asked to specify their return to work status as full-time, part-time, and not return to work after the cancer treatment completion. In the cases with part-time return, the working hours before and after the cancer diagnosis were also recorded. Finally, the third part was the Financial Distress/Financial Well-Being Scale (Prawitz et al., 2006). This scale has 8 items classified according to a ten-point Likert scale ranging from 1(highest financial distress) to 10 (without financial distress). Finally, the sum of each patients scores in all items divided by 8 which represent patients' financial distress. For using the scale, the questionnaire

Table 1. Some Demographic and Cancer-related Characteristics of Participants

\begin{tabular}{|c|c|c|}
\hline \multirow[t]{2}{*}{ Gender } & Male & $102(61.8)$ \\
\hline & Female & 63 (38.2) \\
\hline \multirow[t]{4}{*}{ Education } & Illiterate & $19(11.5)$ \\
\hline & Elementary & 77 (46.7) \\
\hline & Diploma & $44(26.7)$ \\
\hline & University degree & $25(15.29)$ \\
\hline \multirow[t]{2}{*}{ Job } & Handworker & $125(75.8)$ \\
\hline & Governmental staff & $40(24.2)$ \\
\hline \multirow[t]{3}{*}{ Marital status } & Married & $134(81.2)$ \\
\hline & Single & $20(12.1)$ \\
\hline & Widowed / divorced & $11(6.7)$ \\
\hline \multirow[t]{2}{*}{ Location } & City & $132(80)$ \\
\hline & Village & $33(20)$ \\
\hline \multirow[t]{5}{*}{ Type of cancer } & Blood & $76(46.1)$ \\
\hline & Gastro-intestinal & $13(7.9)$ \\
\hline & Breast & $28(17)$ \\
\hline & Colon & $21(12.7)$ \\
\hline & Others & $27(16.4)$ \\
\hline \multirow[t]{4}{*}{ Education of spouse } & Illiterate & $41(29.7)$ \\
\hline & elementary & $49(35.5)$ \\
\hline & Diploma & $35(25.4)$ \\
\hline & University degree & $13(9.4)$ \\
\hline \multirow[t]{3}{*}{ Job of spouse } & Handworker & $48(34.8)$ \\
\hline & Governmental staff & $14(8.5)$ \\
\hline & housekeeper & $76(55.1)$ \\
\hline \multirow[t]{4}{*}{ Education of father } & Illiterate & $11(44)$ \\
\hline & elementary & $9(36)$ \\
\hline & Diploma & $3(12)$ \\
\hline & University degree & $2(8)$ \\
\hline \multirow[t]{3}{*}{ Job of father } & Handworker & $17(68)$ \\
\hline & Governmental staff & $8(32)$ \\
\hline & Age in years, mean (SD) & $43.83(10.49)$ \\
\hline \multirow{2}{*}{\multicolumn{2}{|c|}{ Time passed since diagnosis in month, mean (SD) }} & $36.46(28.83)$ \\
\hline & & $18.68(23.20)$ \\
\hline
\end{tabular}


Table 2. Participants Response to Items of Financial Distress/Financial Well Being Scale

\begin{tabular}{lll}
\hline Questions & Mean & SD \\
\hline Feeling about level of financial stress today & 3.44 & 2.3 \\
Mark satisfaction with present financial situation(on stair steps from 0 to 10) & 4.04 & 2.34 \\
Feeling about current financial situation & 3.9 & 2.13 \\
Worries about being able to meet normal monthly living expense & 3.83 & 2.47 \\
Confidence to find or borrow about \$1,000for a financial emergency & 3.61 & 3.32 \\
Limiting recreational activities because can't afford & 5.46 & 2.75 \\
Frequency of living paycheck to paycheck & 4.35 & 2.28 \\
Perceived stress about personal finances in general & 3.5 & 2.4 \\
Total financial distress score & 3.21 & 1.87 \\
\hline
\end{tabular}

was translated into Persian and then back translated. The Scale accuracy and fluency confirmed by two translator expert in both Persian and English languages. The scales face and content validity were assessed and verified by the expert panel constituted ten faculty members affiliated to Tabriz University of Medical Sciences, Tabriz/Iran. Some minor changes were applied according to expert recommendations. The final version of the questionnaire was tested for reliability in a pilot study involving 25 cancer patients. Cronbach-Alpha coefficient value for Financial Distress/Financial Well-Being Scale was 0.92.

Before data collection, the study proposal was approved by the Regional Ethics Committee of Tabriz University of Medical Sciences. Then, hospital managers' agreements were obtained for data collections. Next, one of researchers was referred to both hospitals. Patients who met criteria for the study were identified and all eligible patients were informed and invited to participate. All patients who participated in the study gave informed consent according to ethic committee guideline. All willing patients were asked to participate in a private interview for data collection to maintain the consistency. Data collection lasted from September to November 2014.

Data were analyzed using SPSS version 13. Some demographic and disease-related characteristics and financial distress of patients were described using descriptive statistics such as the frequency, percentage, mean, and standard deviation. One-way ANOVA and Turkey's Post-hoc tests were used to compare the financial distress of cancer survivors with various statuses of return to work. $\mathrm{p}<0.05$ was considered significant.

\section{Results}

Table 1 shows some demographic and cancer-related characteristics of the participants. As shown in table 1, most of patients were male, married, had elementary education and manual work. Also, most of spouses of married patients were housekeeper and had elementary education.

Overall, 120 cancer survivors (72\%) had returned to work after initial treatments. Of those patients who had returned to work 50 patients $(42 \%)$ had returned to full-time work and 70 patients (58\%) had reduced their work hours and returned to part-time work. The mean of working hours per day in part-time patients had reduced from $12.00(\mathrm{SD}=2.26)$ hour in pre-diagnosis period to 5.24 $(\mathrm{SD}=1.63)$ hour after the return to work.

Table 2 depicts the mean values of patients' responses to all the items of Financial Distress/Financial Well-Being Scale. As shown in table 2, cancer survivors reported high levels of financial distress.

The mean of financial distress scores among cancer survivors who had returned to work as full-time, part-time and had quit working for cancer-related reasons were $4.43(\mathrm{SD}=1.91), 2.94(\mathrm{SD}=1.64)$, and $2.26(\mathrm{SD}=1.45)$ respectively $(\mathrm{p}=0.001)$. In this regard, Tukey's Post-hoc test showed that patients who had returned completely to their former work had significant lower levels of financial distress than those patients who had not returned to work $(\mathrm{p}=0.001)$ or returned partially $(\mathrm{p}=0.001)$.

\section{Discussion}

According to extensive literature review, this is one of the first studies which assessed return to work and its relation to financial distress among Iranian cancer survivors. The study findings showed a total of 120 (72\%) of cancer survivors had returned to work after initial treatments, of which only $50(42 \%)$ patients had returned to full-time work and $70(58 \%)$ patients reduced their daily working hours by nearly $50 \%$. The findings of a systematic review by Spelten et al. (2002) showed that $62 \%$ of cancer survivors (range $30-93 \%$ ) had returned to work. Similarly, in another systematic review Mehnert et al. (2011) were selected and surveyed a total of 64 studies (between 2000 and 2009) and found 62\% (range 24-94\%) of cancer survivors had returned to work. Others studies reported that on an average two-thirds of patients who had worked before their cancer diagnosis returned to work two years after the initial treatments (De Boer et al., 2008; Mehnert and Koch., 2013). However, Feuerstein et al. (2010) reported that physical and mental work abilities had reduced in most of cancer survivors compare to their working performance in pre-diagnosis period. Several studies indicated that on an average $60 \%$ of cancer survivors had returned to work within 1 to 2 years after cancer diagnosis (Spelten et al., 2002; Maunsell et al., 2004; Bradley et al., 2005). So, the findings of this study are consistent with the results obtained in other countries and confirm that a significant percentage of survivors quit working for cancer-related reasons or reduce considerable amounts of their work hours. Return to work can improve the quality of life in cancer survivors and could be a symbol of recovery and return to normal life (Spelten et al., 2002; Kennedy et al., 2007). Also, return to work may help patients to overcome the negative impacts of disease treatments, has positive financial outcome for patients and 
reduce the economic burden of cancer on society (Ferrell et al., 1997; van Muijen et al., 2013).

The study findings furthermore showed that cancer survivors had a high level of financial stress. A systematic review by Bestvina et al. (2014) revealed that financial distress even is prevalent among insured cancer patients and may make it difficult for some of these patients to receive some of costly prescribed treatments. Another study in United States revealed that breast cancer survivors, especially Spanish women, suffered great financial distress (Jagsi et al., 2014). Similarly, the results of other studies also confirmed the high level of financial distress among cancer survivors (Langabeer., 2005; Gooberman-Hill and Sharp., 2013). In our study, cancer survivors also have experienced high levels of financial distress. Cancer diagnosis could be devastating news for patients and their families not only due to the nature of the disease but also because of the constant financial distress caused by the costly treatments (Zaidi et al., 2012). In developing countries the economic conditions are more complicated. In most of these countries, governments undertake little amounts of the cancer costs and most of direct and indirect costs must to pay by the patients and families (Longo et al., 2006).

The present study showed that patients who had returned to their full-time work had significant lower levels of financial distress than those patients who had not returned to work or returned partially. Accordingly, financial distress can be one of the main factors that influence the return to work in cancer patients survivors. Most of participants in Main et al. (2005) study declared that financial issues was an important factor in their decision to return to work. In a further study, authors emphasized on financial distress as one of the important factors associated with return to work by women with breast cancer in France (Fantoni et al., 2010). Other studies also showed that financial concern was an important factor in return to work among cancer survivors (Main et al., 2005; Kennedy et al., 2007). It is worth noting that Spelten et al. (2002) found no significant relationship between patients' incomes and their return to work. So, the findings of this study confirmed the hypothesis that financial stress is an important factor in Iranian cancer survivors' return to work.

The study findings can be used for designing and implanting supportive care programs for cancer survivors. The study finding showed that a significant number of Iranian cancer survivors do not return to work or may reduce almost half of work hours after the treatment completion. Accordingly, due to the importance of returning to work for both patients and the society, appropriate interventions should be designed. Furthermore, special considerations of Iranian health care system regarding the financial difficulties of cancer patients are required.

Despite the strength of this study, it also has some limitations. First, a sample of patients admitted to two medical centers in East Azerbaijan Province in northwest of Iran cannot represent the overall state of return to work and its relation to financial distress among Iranian cancer survivors. Next, in some cases, patients might not disclose their real financial situation and reported it worse than the truth. Also, in this study we examined the patients' financial distress after their return to work. Accordingly, in relation to future research, replicating such studies in other Iranian regions is required. In addition, a longitudinal design can help to discover more information regarding the relationship between return to work and financial distress among cancer survivors.

\section{Acknowledgements}

This is a report of a database from a Master of Science thesis approved by Tabriz University of Medical Sciences. The authors wish to acknowledge all of the patients, whose contribution enabled the production of this article.

\section{References}

Abrahamsen AF, Loge JH, Hannisdal E, Holte H, Kvaloy S (1998). Socio-medical situation for long-term survivors of Hodgkin's disease: a survey of 459 patients treated at one institution. Eur J Cancer, 34, 1865-70.

Afrooz R, Rahmani A, Zamanzadeh V, et al (2014). The nature of hope among Iranian cancer patients. Asian Pac J Cancer Prev, 5, 9307-12.

Bestvina CM, Zullig LL, Yousuf Zafar S (2014). The implications of out-of-pocket cost of cancer treatment in the USA: a critical appraisal of the literature. Future Oncol, 10, 2189-99.

Bradley CJ, Bednarek HL (2002). Employment patterns of long term cancer survivors. Psychooncology, 11, 188-98.

Bradley CJ, Neumark D, Luo Z, Bednarek H, Schenk M (2005). Employment outcomes of men treated for prostate cancer. $J$ Natl Cancer Inst, 97, 958-65.

de Boer AG, Verbeek JH, Spelten ER, et al (2008). Work ability and return-to-work in cancer patients. Br J Cancer, 98,1342-7.

Faghani S, Rahmani A, Parizad N, Mohajjel-Aghdam AR, Hassankhani H, Mohammadpoorasl A (2014). Social support and its predictors among Iranian cancer survivors. Asian Pac J Cancer Prev, 15, 9767-71.

Fantoni SQ, Peugniez C, Duhamel A, et al (2010). Factors related to return to work by women with breast cancer in northern France. J Occup Rehabil, 20, 49-58.

Ferrell BR, Grant MM, Funk B, Otis-Green S, Garcia N (1997). Quality of life in breast cancer survivors as identified by focus groups. Psychooncology, 6, 13-23.

Feuerstein M, Todd BL, Moskowitz MC, Bruns GL, Stoler MR, Nassif T, et al (2010). Work in cancer survivors: a model for practice and research. J Cancer Surviv, 4, 415-37.

Gudbergsson SB, Fosså SD, Borgeraas E, Dahl AA (2006). A comparative study of living conditions in cancer patients who have returned to work after curative treatment. Support Care Cancer, 14, 1020-9.

Hamilton JG, Wu LM, Austin JE, et al (2013). Economic survivorship stress is associated with poor health related quality of life among distressed survivors of hematopoietic stem cell transplantation. Psychooncology, 22, 911-21.

Han KT, Park EC, Kim SJ, et al (2014). Factors affecting the quality of life of Korean cancer survivors who return to the workplace. Asian Pac J Cancer Prev, 15, 8783-8.

Helgeson VS, Cohen S (1996). Social support and adjustment to cancer: reconciling descriptive, correlational, and intervention research. Health Psychol, 15, 135-48.

Hoffman B (2005). Cancer survivors at work: a generation of progress. CA Cancer J Clin, 55, 271-80. 
Jagsi R, Pottow JA, Griffith KA, et al (2014). Long-term financial burden of breast cancer: experiences of a diverse cohort of survivors identified through population-based registries. $J$ Clin Oncol, 32, 1269-76.

Jemal A, Bray F, Center MM, Ferlay J, Ward E, Forman D (2011). Global cancer statistics. CA Cancer J Clin, 61, 69-90.

Johnsson A, Fornander T, Olsson M, et al (2007). Factors associated with return to work after breast cancer treatment. Acta Oncol, 46, 90-6.

Kennedy F, Haslam C, Munir F, Pryce J (2007). Returning to work following cancer: a qualitative exploratory study into the experience of returning to work following cancer. Eur $J$ Cancer Care, 16, 17-25.

Keogh JW, MacLeod RD (2012). Body composition, physical fitness, functional performance, quality of life, and fatigue benefits of exercise for prostate cancer patients: a systematic review. J Pain Symptom Manage, 43, 96-110.

Langabeer J (2006). Predicting financial distress in teaching hospitals. $J$ Health Care Finance, 33, 84-92

Lauzier S, Maunsell E, Drolet M, Coyle D, Hébert-Croteau N, Brisson J, et al (2008). Wage losses in the year after breast cancer: extent and determinants among Canadian women. J Natl Cancer Inst, 100, 321-32.

Longo CJ, Fitch M, Deber RB, Williams AP (2006). Financial and family burden associated with cancer treatment in Ontario, Canada. Support Care Cancer, 14, 1077-85.

Main DS, Nowels CT, Cavender TA, Etschmaier M, Steiner JF (2005). A qualitative study of work and work return in cancer survivors. Psychooncology, 14, 992-1004.

Maunsell E, Brisson C, Dubois L, Lauzier S, Fraser A (1999). Work problems after breast cancer: an exploratory qualitative study. Psychooncology, 8, 467-73.

Maunsell E, Drolet M, Brisson J, Brisson C, Mâsse B, Deschênes L (2004). Work situation after breast cancer: results from a population-based study. J Natl Cancer Inst, 96, 1813-22. Mehnert A (2011). Employment and work-related issues in cancer survivors. Crit Rev Oncol Hematol, 77, 109-30.

Mehnert A, Koch U (2013). Predictors of employment among cancer survivors after medical rehabilitation-a prospective study. Scand J Work Environ Health, 39, 76-87.

Mousavi SM, Gouya MM, Ramazani R, et al (2009). Cancer incidence and mortality in Iran. Ann Oncol, 20, 556-63.

Muzzin LJ, Anderson N, Figueredo A, Gudelis SO (1994). The experience of cancer. Soc Sci Med, 38,1201-08.

Nilsson MI, Olsson M, Wennman Larsen A, Petersson LM, Alexanderson K (2013). Women's reflections and actions regarding working after breast cancer surgery-a focus group study. Psychooncology, 2, 639-44.

Peteet JR (2000). Cancer and the meaning of work. Gen Hosp Psychiatry, 22, 200-5.

Prawitz AD, Garman ET, Sorhaindo B, O'Neill B, Kim J, Drentea $P$ (2006) InCharge financial distress/financial well-being scale: Development, administration, and score interpretation. $J$ Financial Counseling Planning, 17, 34-45.

Rowland JH, Baker F (2005). Introduction: resilience of cancer survivors across the lifespan. Cancer, 104, 2543-8.

Rowland JH, Yancik R (2006). Cancer survivorship: the interface of aging, comorbidity, and quality care. J Natl Cancer Inst, 98, 504-5.

Schultz PN, Beck ML, Stava C, Sellin R (2002). Cancer survivors. Work related issues. AAOHN J, 50, 220-26.

Short PF, Vasey JJ, Tunceli K (2005). Employment pathways in a large cohort of adult cancer survivors. Cancer, 103, 1292-301.

Siegel R, DeSantis C, Virgo K, et al (2012). Cancer treatment and survivorship statistics. CA Cancer J Clin, 62, 220-41.

Spelten ER, Sprangers MA, Verbeek JH (2002). Factors reported to influence the return to work of cancer survivors: a literature review. Psychooncology, 11, 124-31.

Tan FL, Loh SY, Su TT, Veloo VW, Ng LL (2012). Return to work in multi-ethnic breast cancer survivors--a qualitative inquiry. Asian Pac J Cancer Prev, 13, 5791-7.

Taskila-Brandt T, Martikainen R, Virtanen SV, et al (2004). The impact of education and occupation on the employment status of cancer survivors. Eur J cancer, 40, 2488-93.

Timmons A, Gooberman-Hill R, Sharp L (2013). "It's at a time in your life when you are most vulnerable": a qualitative exploration of the financial impact of a cancer diagnosis and implications for financial protection in health. PLoS One, 11, 77549.

Tuncay T (2014). Coping and quality of life in Turkish women living with ovarian cancer. Asian Pac J Cancer Prev, 15, 4005-12.

van Muijen P, Duijts SF, van der Beek AJ, Anema JR (2013). Prognostic factors of work disability in sick-listed cancer survivors. J Cancer Surviv, 7, 582-91.

Wen KY, Gustafson DH (2004). Needs assessment for cancer patients and their families. Health Qual Life Outcomes, $2,11$.

Zaidi AA, Ansari TZ, Khan A (2012). The financial burden of cancer: Estimates from patients undergoing cancer care in a tertiary care hospital. Int J Equity Health, 15, 11. 